\title{
Predictors for diabetic retinopathy in normoalbuminuric people with type 2 diabetes mellitus
}

\author{
Ho Ra' ${ }^{1}$ Ji Han Yoo², Woo Ho Ban², Ho Cheol Song ${ }^{2}$, Seong Su Lee², Sung Rae Kim², Soon Jib Yoo², \\ Yong-Soo Kim², Euy Jin $\mathrm{Choi}^{2}$ and Yong Kyun Kim²,
}

\begin{abstract}
Background: Previous studies have reported that microalbuminuria is an independent risk factor for the prevalence of diabetic retinopathy (DR) in patients with type 2 diabetes mellitus (DM). For this reason, the clinical significance of DR in normoalbuminuric type 2 DM patients may be overlooked. The aim of this study was to investigate the prevalence of DR and predictors for DR in normoalbuminuric patients with type $2 \mathrm{DM}$.

Methods: A total 310 patients with type 2 DM and normoalbuminuria, who were referred to the Department of Ophthalmology for screening of DR were included in this study. DR was clinically graded according to the International Clinical Diabetic Retinopathy guidelines. The urinary albumin excretion rate (UAER) was assessed via 24-hour urine collection and measured by immunoturbidimetric assay. Normoalbuminuria was defined as a UAER $<20 \mu \mathrm{g} / \mathrm{min}$ in 2 out of 3 consecutive tests taken within $2-3$ months.
\end{abstract}

Results: DR of any grade was present in 64/310 (20.7\%) patients. Mild non-proliferative diabetic retinopathy (NPDR) was most prevalent in patients with DR of any grade (36/64, $56 \%)$. The duration of diabetes (OR $1.01,95 \% \mathrm{Cl}$, $1.01-1.02, p<0.001$ ), hemoglobin levels (OR $0.73,95 \% \mathrm{Cl}, 0.59-0.91, \mathrm{p}=0.004)$ and a higher tertile of UAER (OR 4.04, $95 \% \mathrm{Cl}, 1.71-9.57, \mathrm{p}=0.001$ ) had independently significant association with DR. NPDR as well as PDR was more prevalent in patients with higher tertile of UAER compared with those with lower tertile of UAER (NPDR, $p=0.002$ and PDR, $p=0.027$, respectively).

Conclusions: Our findings suggest that patients with normoalbuminuric type 2 DM also require close monitoring for the early detection of DR, especially if they have a higher UAER, longer duration of diabetes, or lower hemoglobin levels.

Keywords: Albuminuria, Risk factor, Diabetic retinopathy, Type 2 diabetes mellitus, Hemoglobin

\section{Background}

Diabetic retinopathy (DR) is one of the leading causes of visual impairment and blindness in people with diabetes mellitus (DM) [1-3]. As the prevalence of DM increases, the development of DR as a microvascular complication of DM also rises. Furthermore, previous studies demonstrated that DR has also been associated with cardiovascular and all cause mortality as well as visual morbidity

\footnotetext{
* Correspondence: drkimyk@catholic.ac.kr

${ }^{2}$ Department of Internal Medicine, College of Medicine, The Catholic

University of Korea, Seoul, South Korea

${ }^{3}$ Department of Internal Medicine, Bucheon Saint Mary's Hospital, Sosa-dong,

Wonmi-gu, Bucheon-si, Geoynggi-do 420-717, South Korea

Full list of author information is available at the end of the article
}

in patients with type $2 \mathrm{DM}[4,5]$, which adds value to investigating the prevalence and risk factors for DR.

Microalbuminuria is a marker of endothelial dysfunction and may influence on alterations in the microvasculature of retina and kidneys. Previous studies have demonstrated that microalbuminuria is predictive for certain diabetic complications such as diabetic nephropathy, and is a useful marker for early detection and treatment [6]. Regarding the association between microalbuminuria and DR, microalbuminuria has been demonstrated to be an independent risk factor for the incidence of DR in patients with type 1 DM [6-9]. However, in patients with type $2 \mathrm{DM}$, it is controversial

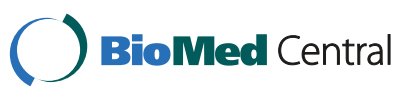

(c) 2012 Ra et al.; licensee BioMed Central Ltd. This is an Open Access article distributed under the terms of the Creative Commons Attribution License (http://creativecommons.org/licenses/by/2.0), which permits unrestricted use, distribution, and reproduction in any medium, provided the original work is properly cited. 
whether microalbuminuria is independently associated with the incidence of DR $[6,10,11]$. These findings suggest that DR might develop in patients with type 2 DM without microalbuminuria. Furthermore, previous studies reported that DR is prevalent in normoalbuminuric patients with type $2 \mathrm{DM}$ and its prevalence is $\sim 10-30 \%$ [11-13]. However, there are few data concerning the prevalence of DR according to the severity and predictors for DR in normoalbuminuric patients with type 2 DM. Establishing the prevalence of DR according to the severity and predictors for DR may be helpful for early detection and treatment of DR in normoalbuminuric patients with type $2 \mathrm{DM}$. Therefore, the purpose of this study was to investigate the prevalence of DR according to the severity and predictors for DR in normoalbuminuric patients with type $2 \mathrm{DM}$.

\section{Materials and methods}

\section{Study population}

This was a retrospective cross-sectional study. The present study included patients with type $2 \mathrm{DM}$ and normoalbuminuria, who were referred to the Department of Ophthalmology for screening of DR and underwent a dilated fundus examination and fundus photographic evaluation at the Bucheon Saint Mary's Hospital between July 2005 and December 2007. Type 2 DM was diagnosed if the patients with a fasting plasma glucose level $\geq 126 \mathrm{mg} / \mathrm{dl}$ or a 2 -h post-glucose level after a 75 -g oral glucose tolerance test $\geq 200 \mathrm{mg} / \mathrm{dl}$ [14]. Patients who were treated by diet alone or in combination with oral hypoglycemic agents or they had fasting serum C-peptide values greater than $1.0 \mathrm{ng} / \mathrm{mL}$ when administered insulin were also categorized as type 2 DM. Normoalbuminuria was defined as a urinary albumin excretion rate $(\mathrm{UAER})<20 \mu \mathrm{g} / \mathrm{min}$ in 2 out of 3 consecutive tests taken within $2-3$ months [15]. The exclusion criteria were 1) an age $<18$ years or $>80$ years, 2) accelerated hypertension 3) pregnancy, 4) malignancies, 5) severely disabled patients such as hepatic failure or heart failure, 6) schizophrenia, 7) goiter, and 8) acute systemic infection. The study protocol was approved by the local ethical committee, and this study was conducted according to the principles of the Declaration of Helsinki.

\section{Ophthalmic examination and definition of diabetic retinopathy}

Each participant underwent a comprehensive ophthalmic examination that included automated refraction (RK-F1, Canon), non-contact tonometry (TX-F, Canon), lens grading at the slit lamp, and stereoscopic fundus examination using an indirect ophthalmoscope, and a slit lamp biomicroscope with a "superfield lens" (Volk, Mentor, OH, USA) after pupil dilatation with $1.0 \%$ tropicamide and $10 \%$ phenylephrine. Fundus photographs $\left(45^{\circ}\right)$ were taken from both eyes of each participant using a digital fundus camera (VX-10i, Kowa, Japan). The photographs were taken in 1-field per eye, centered on the macula. Diagnosis of DR was made by a trained ophthalmologist by an indirect ophthalmoscopic examination based on the presence of clinical features in the fundus of both eyes following the International Clinical Diabetic Retinopathy guidelines, and classified as (i) no apparent retinopathy, (ii) mild nonproliferative diabetic retinopathy (NPDR), (iii) moderate NPDR, (iv) severe NPDR, or (iv) proliferative diabetic retinopathy (PDR) [16].

\section{Clinical information and laboratory analysis}

Clinical information was assessed from the written and electronic medical records, and this information included the medical history, current medications and laboratory data. The collected data included age, gender, body mass index (BMI), systolic and diastolic blood pressures, the duration of diabetes, serum creatinine, hemoglobin and albumin levels, total cholesterol and high-density lipoprotein (HDL) cholesterol levels, triglyceride and serum uric acid levels, the UAER, the homeostasis model for insulin resistance (HOMA-IR) score, lipoprotein (a) and high-sensitivity C-reactive protein (hs-CRP) levels. Drug histories in relation to antihypertensive agents including renin-angiotensin system (RAS) inhibitors were also evaluated. Fasting venous blood samples were taken for the determination of the serum level of total cholesterol, HDL cholesterol and triglyceride. The UAER was assessed via 24 hour urine collection and measured by immunoturbidimetric assay using Roche/Hitachi MODULAR automated clinical chemistry analyzers (Roche Diagnostic, GmbH, Mannheim, Germany). The BMI was calculated as weight $(\mathrm{kg}) /$ height $\left(\mathrm{m}^{2}\right)$. The blood pressure was measured twice, 5 minutes apart, using a random zero sphygmomanometer with the patient seated after 10 minutes of rest. The estimated GFR (eGFR) was calculated using the Modification of Diet in Renal Disease four-variable equation at the time of CT scanning: eGFR $=186 x$ serum creatinine $^{-1.154}$ xage $^{-0.203} \mathrm{x} 1.212$ (if black) $\mathrm{x} 0.742$ (if female) [17]. The HOMA-IR was calculated with the following formula: [Fasting insulin $(\mu \mathrm{IU} / \mathrm{mL}) \times$ fasting plasma glucose $(\mathrm{mmol} / \mathrm{L})] / 22.5$ [18].

\section{Statistics}

The data for continuous variables with a normal distribution is expressed as means \pm SDs and the data for the continuous variables without a normal distribution is expressed as medians with interquartile ranges. The Student's $t$-test or Mann-Whitney test were used, as appropriate, to determine differences in continuous variables. 
Categorical variables are presented as percentage. The Pearson's chi-square test or Fisher's exact test, as appropriate, was used to determine the differences in categorical variables. Both univariate and multivariate logistic regression analyses were performed to determine the various risk factors for the presence of DR. From the univariate analysis, variables with $\mathrm{p}<0.05$ and those which were already established as risk factors were included in the multivariate logistic regression analysis. These variables included age, gender, systolic blood pressure, duration of DM, eGFR, hemoglobin, use of RAS inhibitors and urinary albumin excretion rate. $P$ values $<0.05$ were considered statistically significant. The statistical analyses were performed using SPSS 15.0 software (Chicago, IL, USA).

\section{Results}

A total 310 patients were enrolled in this study. The mean age of enrolled patients was $54 \pm 14$ years (median, 54 years; interquartile range, 46 - 65 years). This study included 153 males (49.4\%) and 157 females (50.6\%). Median duration of diabetes was 29 months (interquartile range, 2 - 110 months) and the mean eGFR was $97 \pm 25 \mathrm{ml} / \mathrm{min} / 1.73 \mathrm{~m}^{2}$.

Table 1 shows the prevalence of DR according to the diabetic retinopathy staging system presented by the International Clinical Diabetic Retinopathy guidelines. DR of any grade was present in 64/310 (20.7 \%) patients. Of the patients with DR of any grade, 54/64 (84.4\%) had NPDR and 10/64 (15.6\%) had PDR. Of the patients with NPDR, 36/54 (66.7 \%) had mild NPDR, 5/54 (9.3 \%) had moderate NPDR and 13/54 (24.1\%) had severe NPDR, respectively.

Comparisons of clinical characteristics between the patients with DR and without DR are shown in Table 2. The patients with DR were older than those without DR and DR was more prevalent in females than in males. The patients with DR had lower BMI, higher systolic blood pressure, longer duration of diabetes, lower eGFR, lower hemoglobin levels, lower serum total cholesterol

Table 1 Prevalence of diabetic retinopathy according to the diabetic retinopathy staging system presented by the International Clinical Diabetic Retinopathy guidelines in normoalbuminuric people with type 2 DM

\begin{tabular}{lc}
\hline & Number of patients $(\mathbf{n}=\mathbf{3 1 0})$ \\
\hline No diabetic retinopathy & $246(79.4)$ \\
NPDR, mild & $36(11.6)$ \\
NPDR, moderate & $5(1.6)$ \\
NPDR, severe & $13(4.2)$ \\
PDR & $10(3.2)$ \\
\hline
\end{tabular}

Data are expressed as $\mathrm{n}(\%)$.

Abbreviations: NPDR non-proliferative diabetic retinopathy, $P D R$ proliferative diabetic retinopathy.
Table 2 Comparisons of clinical characteristics between the patients with DR and without DR

\begin{tabular}{|c|c|c|c|}
\hline Clinical characteristics & No $D R(n=246)$ & DR $(n=64)$ & $P$ value \\
\hline Age, years & $53 \pm 13$ & $61 \pm 12$ & $<0.001$ \\
\hline Female, n (\%) & $114(46.3)$ & $43(67.2)$ & 0.003 \\
\hline $\mathrm{BMI}, \mathrm{kg} / \mathrm{m}^{2}$ & $25.0 \pm 3.7$ & $23.9 \pm 3.0$ & 0.022 \\
\hline Systolic blood pressure, $\mathrm{mmHg}$ & $127 \pm 14$ & $132 \pm 17$ & 0.018 \\
\hline Diastolic blood pressure, $\mathrm{mmHg}$ & $77 \pm 10$ & $77 \pm 9$ & 0.836 \\
\hline Duration of diabetes, months & $17(1-75)$ & $117(60-191)$ & $<0.001$ \\
\hline Serum creatinine, mg/dL & $0.8 \pm 0.2$ & $0.8 \pm 0.2$ & 0.797 \\
\hline Estimated GFR, ml/min/1.73 $\mathrm{m}^{2}$ & $99 \pm 25$ & $89 \pm 22$ & 0.003 \\
\hline Hemoglobin, g/dL & $13.9 \pm 1.8$ & $12.6 \pm 1.7$ & $<0.001$ \\
\hline Serum albumin, g/dL & $4.4 \pm 0.4$ & $4.3 \pm 0.4$ & 0.111 \\
\hline Serum total cholesterol, mg/dL & $187 \pm 42$ & $174 \pm 44$ & 0.049 \\
\hline Serum triglyceride, $\mathrm{mg} / \mathrm{dL}$ & $167 \pm 119$ & $181 \pm 132$ & 0.411 \\
\hline Serum HDL, mg/dL & $51 \pm 14$ & $48 \pm 17$ & 0.076 \\
\hline Serum uric acid, mg/dL & $4.3 \pm 1.4$ & $4.5 \pm 1.6$ & 0.550 \\
\hline $\begin{array}{l}\text { Urinary albumin excretion, } \\
\mu \mathrm{g} / \mathrm{min}\end{array}$ & $5.92 \pm 3.50$ & $8.97 \pm 5.07$ & $<0.001$ \\
\hline Hemoglobin A1C & $9.2 \pm 2.5$ & $9.1 \pm 1.9$ & 0.741 \\
\hline HOMA-IR & $3.4 \pm 4.6$ & $4.0 \pm 4.3$ & 0.347 \\
\hline Lipoprotein (a), (IU/L) & $135(46-341)$ & $171(42-387)$ & 0.496 \\
\hline hs-CRP, mg/dL & $0.2(0.1-0.9)$ & $0.2(0.1-0.7)$ & 0.854 \\
\hline Use of RAS inhibitors, n (\%) & $68(27.6)$ & $33(51.6)$ & $<0.001$ \\
\hline
\end{tabular}

Values are expressed as means $\pm \mathrm{SD}$, medians (interquartile range) or $\mathrm{n}(\%)$. Abbreviations: $D R$ diabetic retinopathy, BMI body mass index, GFR glomerular filtration rate, $H D L$ high-density lipoprotein, HOMA-IR homeostasis model for insulin resistance, $h s-C R P$ high-sensitivity $C$-reactive protein,

$R A S$ renin-angiotensin system.

levels and higher UAER compared with those without DR. The number of patients using RAS inhibitors was 101 (32.6\%) and the patients with DR had higher prevalence of using RAS inhibitors compared with those without DR. In univariate logistic regression analysis with the presence of DR as dependent variable, age, gender, BMI, systolic blood pressure, duration of diabetes, eGFR, hemoglobin levels, use of RAS inhibitors and higher tertile of UAER were significantly associated with the presence of DR (Table 3). Multivariate logistic regression analysis to determine the predictor of DR in normolabuminuric people with type $2 \mathrm{DM}$ are shown in Table 4. Data revealed that the duration of diabetes (OR 1.01, $95 \%$ CI, $1.01-1.02, \mathrm{p}<0.001$ ), hemoglobin levels (OR 0.73, $95 \%$ CI, $0.59-0.91, \mathrm{p}=0.004)$, and a higher tertile of UAER (OR 4.04, 95 \% CI, $1.71-9.57, \mathrm{p}=0.001$ ) had independently significant association with DR. As the UAER was a strong predictor of the presence for DR, we analyzed the prevalence of diabetic retinopathy according to the tertiles of urinary albumin excretion rate (Table 5). NPDR as well as PDR was more prevalent in patients with a higher tertile of UAER compared with 
Table 3 Univariate logistic regression analysis with diabetic retinopathy as a dependent variable in normolabuminuric people with type 2 DM

\begin{tabular}{|c|c|c|c|}
\hline & \multicolumn{3}{|c|}{ DR } \\
\hline & Odds ratio & $95 \% \mathrm{Cl}$ & $P$ value \\
\hline Age & 1.05 & $1.03-1.08$ & $<0.001$ \\
\hline Gender (female) & 2.37 & $1.33-4.23$ & 0.003 \\
\hline BMl & 0.91 & $0.83-0.99$ & 0.023 \\
\hline Systolic blood pressure & 1.02 & $1.00-1.04$ & 0.019 \\
\hline Diastolic blood pressure & 1.00 & $0.98-1.03$ & 0.835 \\
\hline Duration of diabetes & 1.01 & $1.01-1.02$ & $<0.001$ \\
\hline Serum creatinine & 1.16 & $0.37-3.70$ & 0.797 \\
\hline Estimated GFR & 0.98 & $0.97-0.99$ & 0.004 \\
\hline Hemoglobin & 0.67 & $0.57-0.79$ & $<0.001$ \\
\hline Serum albumin & 0.57 & $0.29-1.14$ & 0.573 \\
\hline Serum total cholesterol & 0.99 & $0.99-1.00$ & 0.050 \\
\hline Serum triglyceride & 1.00 & $1.00-1.00$ & 0.411 \\
\hline Serum HDL & 0.98 & $0.96-1.00$ & 0.077 \\
\hline Serum uric acid & 1.06 & $0.88-1.28$ & 0.549 \\
\hline Hemoglobin A1c & 0.96 & $0.88-1.07$ & 0.418 \\
\hline HOMA-IR & 0.98 & $0.87-1.10$ & 0.981 \\
\hline Lipoprotein (a) & 1.0 & $1.0-1.0$ & 0.876 \\
\hline hs-CRP & 1.01 & $0.99-1.04$ & 0.375 \\
\hline Use of RAS inhibitors & 2.79 & $1.59-4.90$ & $<0.001$ \\
\hline \multicolumn{4}{|l|}{$\begin{array}{l}\text { Urinary albumin excretion } \\
\text { rate tertiles }\end{array}$} \\
\hline I $(<4.26 \mu \mathrm{g} / \mathrm{min})$ & 1 & - & - \\
\hline II (4.26 -7.21 $\mu \mathrm{g} / \mathrm{min})$ & 1.38 & $0.62-3.08$ & 0.433 \\
\hline III (> $7.21 \mu \mathrm{g} / \mathrm{min})$ & 4.08 & $1.97-8.42$ & $<0.001$ \\
\hline
\end{tabular}

Abbreviations: $D R$ diabetic retinopathy, $B M I$ body mass index, GFR glomerular filtration rate, $H D L$ high-density lipoprotein, HOMA-IR homeostasis model for insulin resistance, $h s-C R P$ high-sensitivity C-reactive protein,

$R A S$ renin-angiotensin system.

those with a lower tertile of UAER (NPDR, $\mathrm{p}=0.002$ and PDR, $\mathrm{p}=0.027$, respectively).

\section{Discussion}

In this study, we reported the prevalence of diabetic retinopathy according to the severity and predictors for DR in normoalbuminuric patients with type 2 DM. Previous studies reported that microalbuminuria was independently associated with the prevalence of NPDR and PDR in patients with type 2 DM [11,12,19-21]. For this reason, the clinical significance of DR in normoalbuminuric type 2 DM patients may be overlooked. Normoalbuminuria is much more prevalent than microalbuminuria and macroalbuminuria in patients with type $2 \mathrm{DM}$. The prevalence of normoalbuminuria was reported to be 68 - $81 \%$ in patients with type $2 \mathrm{DM}$ in population-based cross sectional studies [12,22,23]. In spite of the high prevalence of normoalbuminuria in patients with type $2 \mathrm{DM}$, the prevalence of diabetic retinopathy according to the severity and predictors for DR in normoalbuminuric patients with type $2 \mathrm{DM}$ has not been well studied.

In our study, the prevalence of DR with any grade was $20.7 \%$, which is similar to the prevalence of DR as $10-$ $30 \%$ reported in previous studies on normoalbuminuric patients with type 2 DM [11-13]. Our study also analyzed the prevalence of DR according to its severity. NPDR was more prevalent than PDR, and mild NPDR was most prevalent in patients with NPDR with any grade. Our findings mean that DR is prevalent even in normoalbuminuric patients with type $2 \mathrm{DM}$, and mild NPDR is most the common form according to the DR staging system presented by the International Clinical Diabetic Retinopathy guidelines.

In our study, we showed that the duration of diabetes, hemoglobin levels, and UAER were independent predictors for the presence of DR in normoalbuminuric patients with type 2 DM. Interestingly, the UAER was the strongest predictor for the presence of DR in normoalbuminuric patients with type $2 \mathrm{DM}$ even after adjustment for age, gender, systolic blood pressure, duration of DM, eGFR and use of RAS inhibitors. Previous studies have reported that microalbuminuria is associated with the prevalence of DR in patients with type 2 DM [19-21]. Most of the previous studies included type 2 DM patients with not only normoalbuminuria, but also microalbuminuria and macroalbuminuria. It has not been well known whether the UAER could predict the presence of DR even in normoalbuminuric patients with

Table 4 Multivariate logistic regression analysis to determine the predictor of diabetic retinopathy in normolabuminuric people with type 2 DM

\begin{tabular}{lccr}
\hline & \multicolumn{3}{c}{ DR } \\
\cline { 2 - 4 } & Odds ratio & $\mathbf{9 5 \% ~ C l}$ & P value \\
\hline Age & 1.00 & $0.97-1.04$ & 0.872 \\
Gender (female) & 1.08 & $0.51-2.28$ & 0.837 \\
Systolic blood pressure & 1.02 & $0.99-1.04$ & 0.197 \\
Duration of diabetes & 1.01 & $1.01-1.02$ & $<0.001$ \\
Estimated GFR & 1.00 & $0.99-1.02$ & 0.985 \\
Hemoglobin & 0.73 & $0.59-0.91$ & 0.004 \\
Use of RAS inhibitors & 1.83 & $0.92-3.62$ & 0.084 \\
Urinary albumin excretion & & & \\
rate tertiles & & & \\
I (< 4.26 $\mu \mathrm{g} / \mathrm{min})$ & 1 & - & - \\
II (4.26 -7.21 $\mu \mathrm{g} / \mathrm{min})$ & 1.34 & $0.52-3.44$ & 0.543 \\
III $(>7.21 \mu \mathrm{g} / \mathrm{min})$ & 4.04 & $1.71-9.57$ & 0.001 \\
\hline Ab & & &
\end{tabular}

Abbreviations: $D R$, diabetic retinopathy; GFR, glomerular filtration rate; $R A S$, renin-angiotensin system. 
Table 5 Prevalence of diabetic retinopathy by the International Clinical Diabetic Retinopathy guidelines according to the tertiles of urinary albumin excretion rate in normoalbuminuric people with type 2 DM

\begin{tabular}{|c|c|c|c|c|}
\hline & & ary albumin excretion & & \\
\hline & $\begin{array}{c}\text { Tertile I } \\
(<4.26 \mu \mathrm{g} / \mathrm{min}) \\
\mathrm{n}=103\end{array}$ & $\begin{array}{c}\text { Tertile II } \\
(4.26-7.21 \mu \mathrm{g} / \mathrm{min}) \\
\mathrm{n}=104\end{array}$ & $\begin{array}{c}\text { Tertile III } \\
(>7.21 \mu \mathrm{g} / \mathrm{min}) \\
\mathrm{n}=103\end{array}$ & $P$ value \\
\hline No DR & $91(88.3)$ & $88(84.6)$ & $67(65.0)$ & $<0.001$ \\
\hline NPDR & $11(10.7)$ & $14(13.5)$ & $29(28.2)$ & 0.002 \\
\hline NPDR, mild & $8(7.8)$ & $8(7.7)$ & $20(19.4)$ & \\
\hline NPDR, moderate & $0(0)$ & $3(2.9)$ & $2(1.9)$ & \\
\hline NPDR, severe & $3(2.9)$ & $3(2.9)$ & $7(6.8)$ & \\
\hline PDR & $1(1.0)$ & $2(1.9)$ & $7(6.8)$ & 0.027 \\
\hline
\end{tabular}

Data are expressed as $\mathrm{n}(\%)$.

Abbreviations: NPDR non-proliferative diabetic retinopathy, PDR proliferative diabetic retinopathy.

type 2 DM. To our knowledge, this study is the first to investigate the association between UAER and the presence of DR in normoalbuminuric patients with type 2 DM. Furthermore, in our study, not only NPDR, but also PDR, was more prevalent in patients with a higher tertile of UAER compared with those with a lower tertile of UAER, which means that UAER was associated with the severity of DR in normoalbuminuric people with type 2 DM. Our findings suggest that even in patients with normoalbuminuric type $2 \mathrm{DM}$, close monitoring for DR might be needed for the early detection of DR if they have a higher UAER.

In our study, a longer duration of diabetes and lower hemoglobin levels were also independently associated with the prevalence of DR. The duration of diabetes is a well known predictor for the presence of DR in patients with type $2 \mathrm{DM}[12,21,24]$. The duration of diabetes is regarded as a marker for long-term exposure to hyperglycemia. Therefore, longer duration of diabetes may contribute the prevalence of DR. Lower hemoglobin levels were an independent predictor for the occurrence and severity of DR in the previous studies [21,25]. There is no clear evidence for the mechanism underlying the association of anemia with DR. However, there are some possible mechanisms of how anemia can adversely affect medical outcomes. Hypoxia may alter angiogenesis, capillary permeability, vasomotor response and cell survival [26], which may contribute the adverse medical outcomes including occurrence and progression of DR. Our findings add value by supporting the use of the duration of diabetes and hemoglobin levels as additional predictors for the presence of DR in patients with normoalbuminuric type $2 \mathrm{DM}$.

Our study has some limitations. First, this study was a cross-sectional study and the sample size was relatively small. A larger prospective study may further elucidate the occurrence and predictors of DR in patients with normoalbuminuric type $2 \mathrm{DM}$. Second, this study is single center study; therefore, the generalizability of our results to other ethnic groups with type 2 DM is uncertain.

\section{Conclusions}

DR is prevalent even in normoalbuminuric patients with type $2 \mathrm{DM}$, and mild NPDR is the most common form. The duration of diabetes, hemoglobin levels, and UAER were independent predictors for the presence of DR, and the UAER was the strongest predictor for DR. Our findings suggest that even in patients with normoalbuminuric type $2 \mathrm{DM}$, close monitoring for DR might be needed for early detection of DR, especially if they have a higher UAER, longer duration of diabetes, or lower hemoglobin levels.

Competing interests

The authors declare that they have no competing interests.

\section{Acknowledgements}

This work was supported by a grant of the Korea Healthcare Technology R\&D Project, Ministry of Health and Welfare, Republic of Korea (A102065) and the Institute of Clinical Medicine Research of Bucheon St. Mary's Hospital, Research Fund, 2010 (BCMC10AA06)

\section{Author details}

${ }^{1}$ Department of Ophthalmology and Visual Science, College of Medicine, The Catholic University of Korea, Seoul, South Korea. ${ }^{2}$ Department of Internal Medicine, College of Medicine, The Catholic University of Korea, Seoul, South Korea. ${ }^{3}$ Department of Internal Medicine, Bucheon Saint Mary's Hospital, Sosa-dong, Wonmi-gu, Bucheon-si, Geoynggi-do 420-717, South Korea.

\section{Author's contributions}

HR, JHY, WHB, HCS, SSL, SRK, SJY, YSK, and EJC contributed in execution, analysis and manuscript drafting. YKK contributed in study design, execution, analysis, manuscript drafting and critical discussion. All authors read and approved the final manuscript.

Received: 1 February 2012 Accepted: 2 July 2012

Published: 2 July 2012

\section{References}

1. Resnikoff S, Pascolini D, Etya'ale D, Kocur I, Pararajasegaram R, Pokharel GP, Mariotti SP: Global data on visual impairment in the year 2002. Bull World Health Organ 2004, 82:844-851.

2. Stolk RP, Vingerling JR, de Jong PT, Dielemans I, Hofman A, Lamberts SW, Pols HA, Grobbee DE: Retinopathy, glucose, and insulin in an elderly population. The Rotterdam Study. Diabetes 1995, 44:11-15. 
3. Delcourt C, Massin P, Rosilio M: Epidemiology of diabetic retinopathy: expected vs reported prevalence of cases in the French population. Diabetes Metab 2009, 35:431-438.

4. van Hecke MV, Dekker JM, Stehouwer CD, Polak BC, Fuller JH, Sjolie AK, Kofinis A, Rottiers R, Porta M, Chaturvedi N, EURODIAB prospective complications study: Diabetic retinopathy is associated with mortality and cardiovascular disease incidence: the EURODIAB prospective complications study. Diabetes Care 2005, 28:1383-1389.

5. Juutilainen A, Lehto S, Rönnemaa T, Pyörälä K, Laakso M: Retinopathy predicts cardiovascular mortality in type 2 diabetic men and women. Diabetes Care 2007, 30:292-299.

6. Newman DJ, Mattock MB, Dawnay AB, Kerry S, McGuire A, Yaqoob M, Hitman GA, Hawke C: Systematic review on urine albumin testing for early detection of diabetic complications. Health Technol Assess 2005, 9:163. iii-vi, xiii.

7. Lövestam-Adrian M, Agardh E, Agardh CD: The temporal development of retinopathy and nephropathy in type 1 diabetes mellitus during 15 years diabetes duration. Diabetes Res Clin Pract 1999, 45:15-23.

8. Marshall SM, Alberti KG: Comparison of the prevalence and associated features of abnormal albumin excretion in insulin-dependent and noninsulin-dependent diabetes. Q J Med 1989, 70:61-71.

9. Krolewski AS, Warram JH, Rand LI, Christlieb AR, Busick EJ, Kahn CR: Risk of proliferative diabetic retinopathy in juvenile-onset type I diabetes: a 40-yr follow-up study. Diabetes Care 1986, 9:443-452.

10. Potisat S, Srisubat A, Krairttichai U, Jongsareejit A: The relationship between microalbuminuria by using urine dipsticks and diabetic retinopathy in type 2 diabetes. J Med Assoc Thai 2008, 91:846-851.

11. Manaviat MR, Afkhami M, Shoja MR: Retinopathy and microalbuminuria in type II diabetic patients. BMC Ophthalmol 2004, 4:9.

12. Rani PK, Raman R, Gupta A, Pal SS, Kulothungan V, Sharma T: Albuminuria and Diabetic Retinopathy in Type 2 Diabetes Mellitus Sankara Nethralaya Diabetic Retinopathy Epidemiology And Molecular Genetic Study (SN-DREAMS, report 12). Diabetol Metab Syndr 2011, 3:9.

13. An JH, Cho YM, Yu HG, Jang HC, Park KS, Kim SY, Lee HK: The clinical characteristics of normoalbuminuric renal insufficiency in Korean type 2 diabetic patients: a possible early stage renal complication. J Korean Med Sci 2009, 24(Suppl):75-81.

14. Alberti KG, Zimmet PZ: Definition, diagnosis and classification of diabetes mellitus and its complications. Part 1: diagnosis and classification of diabetes mellitus provisional report of a WHO consultation. Diabet Med 1998, 15:539-553.

15. Molitch ME, DeFronzo RA, Franz MJ, Keane WF, Mogensen CE, Parving HH, Steffes MW, American Diabetes Association: Nephropathy in diabetes. Diabetes Care 2004, 27(Suppl 1):79-83.

16. Wilkinson CP, Ferris FL, Klein RE, Lee PP, Agardh CD, Davis M, Dills D, Kampik A, Pararajasegaram R, Verdaguer JT, Global Diabetic Retinopathy Project Group: Proposed international clinical diabetic retinopathy and diabetic macular edema disease severity scales. Ophthalmology 2003, 110:1677-1682.

17. Levey AS, Bosch JP, Lewis JB, Greene T, Rogers N, Roth D: A more accurate method to estimate glomerular filtration rate from serum creatinine: a new prediction equation. Modification of Diet in Renal Disease Study Group. Ann Intern Med 1999, 130:461-470.

18. Haffner SM, Miettinen H, Stern MP: The homeostasis model in the San Antonio Heart Study. Diabetes Care 1997, 20:1087-1092.

19. Boelter MC, Gross JL, Canani LH, Costa LA, Lisboa HR, Três GS, Lavinsky J, Azevedo MJ: Proliferative diabetic retinopathy is associated with microalbuminuria in patients with type 2 diabetes. Braz J Med Biol Res 2006, 39:1033-1039.

20. Sobngwi E, Mbanya JC, Moukouri EN, Ngu KB: Microalbuminuria and retinopathy in a diabetic population of Cameroon. Diabetes Res Clin Pract 1999, 44:191-196.

21. Ajoy Mohan VK, Nithyanandam S, Idiculla J: Microalbuminuria and low hemoglobin as risk factors for the occurrence and increasing severity of diabetic retinopathy. Indian J Ophthalmol 2011, 59:207-210.

22. Unnikrishnan RI, Rema M, Pradeepa R, Deepa M, Shanthirani CS, Deepa R, Mohan V: Prevalence and risk factors of diabetic nephropathy in an urban South Indian population: the Chennai Urban Rural Epidemiology Study (CURES 45). Diabetes Care 2007, 30:2019-2024.

23. Pradeepa R, Rema M, Vignesh J, Deepa M, Deepa R, Mohan V: Prevalence and risk factors for diabetic neuropathy in an urban south Indian population: the Chennai Urban Rural Epidemiology Study (CURES-55). Diabet Med 2008, 25:407-412.

24. Kim JH, Kwon HS, Park YM, Lee JH, Kim MS, Yoon KH, Lee WC, Cha BY, Son HY: Prevalence and associated factors of diabetic retinopathy in rural Korea: the Chungju metabolic disease cohort study. J Korean Med Sci 2011, 26:1068-1073.

25. Davis MD, Fisher MR, Gangnon RE, Barton F, Aiello LM, Chew EY, Ferris FL 3rd, Knatterud GL: Risk factors for high-risk proliferative diabetic retinopathy and severe visual loss: Early Treatment Diabetic Retinopathy Study Report \#18. Invest Ophthalmol Vis Sci 1998, 39:233-252.

26. Irace C, Scarinci F, Scorcia V, Bruzzichessi D, Fiorentino R, Randazzo G, Scorcia G, Gnasso A: Association among low whole blood viscosity, haematocrit, haemoglobin and diabetic retinopathy in subjects with type 2 diabetes. Br J Ophthalmol 2011, 95:94-98.

doi:10.1186/1758-5996-4-29

Cite this article as: Ra et al:: Predictors for diabetic retinopathy in normoalbuminuric people with type 2 diabetes mellitus. Diabetology \& Metabolic Syndrome 2012 4:29.

\section{Submit your next manuscript to BioMed Central and take full advantage of:}

- Convenient online submission

- Thorough peer review

- No space constraints or color figure charges

- Immediate publication on acceptance

- Inclusion in PubMed, CAS, Scopus and Google Scholar

- Research which is freely available for redistribution

Submit your manuscript at www.biomedcentral.com/submit
C) Biomed Central 